\title{
Geographic Information Systems (GIS) Based Accessibility Modelling Approach in Micro Scale Considering Physically Disabled Users: Case Study of Mimar Muzaffer Campus, Selcuk University
}

\section{Abstract}

The concept of physical accessibility refers to the availability, capability, comfort, convenience of transportation processes considering different urban obstacles / barriers and costs. In this context, there are many approaches for the measurement and evaluation of physical accessibility in the literature which are used extensively as a decision support especially in transportation, geography and city and regional planning related disciplines.

Although there are large number of modelling approaches on physical accessibility modelling in macro scales (such as national, regional, city and town scales), the research on physical accessibility modelling, in micro scales (such as street, human, neighbourhood scales), which could
Keywords: Accessibility modeling, physically disabled users, physical obstacles / barriers / transitions, micro scale (street, human, neighborhood scales)

*Asst. Prof. Dr. Faculty of Architecture and Design, Dept. of Urban and Regional Planning, Konya Technical University, Konya, Turkey. E-mail: kivancertugay@gmail.com Orcid ID: http://orcid.org/0000-0001-95933548 
consider all the details of the perceived space seem to be extremely limited.

This study, which emerged from this lack of accessibility modelling literature, proposes a Geographical Information System (GIS) supported methodology to demonstrate how physical obstacles / barriers such as "buildings, landscape areas, walls, steps, stairs, pits, unfitted street furniture, other (garbage, rubbles, trees etc. that prevent access) etc." and transitions such as "ramps with appropriate slope, elevators and/or "removing walls / steps" could be defined in GIS environment and how access and circulation in (outdoor) urban space could be modelled considering these physical obstacles / barriers and transitions especially taking physically disabled users (users using wheelchair, bicycle, baby's car, market car etc.) into consideration in the micro scale.

The proposed accessibility modelling methodology is conducted at Selçuk University, Faculty of Architecture, Mimar Muzaffer Campus Area. A polyline-based spatial GIS database has been developed to demonstrate how physical barriers and transitions could be modelled in micro scale in GIS environment in order to evaluate physical accessibility. The results of the study could provide an accessibility based decision support environment by visualizing and presenting how physical obstacles in urban space prevent physically disabled users from access and circulation and how the elimination or removal of these physical obstacles and creation of transitions will create a difference in access and circulation for the users in a comparable manner especially in micro scale.

This study is thought to make a significant contribution to increase accessibility levels of physically disabled users (users using wheelchair, bicycle, baby's car, market car etc.) in the outdoor urban areas in terms of demonstrating their accessibility and circulation capabilities.

The primitive experimental model related with this research was carried out with the participants of the accessibility measurement and modelling session at the 3rd National Disability Workshop which is held in Selcuk University, Mimar Muzaffer Campus dated 2-3 May 2018.

\section{INTRODUCTION}

The concept of physical accessibility is an important concept that reveals the level of ability, comfort, convenience etc. of transportation against different urban barriers and transitions.

Physical accessibility measures are widely used especially in macro scales (such as national, regional, city and town scales) to check the benefits of urban and regional plans and/or transportation networks as a planning control tool. They help to evaluate proximity and availability of several urban/rural services like health, education, recreation, emergency or trade etc. by considering population (supply and demand relations) and several transportation types like by seaway, airway, railway, road 
Geographic Information Systems (GIS) Based Accessibility Modeling Approach in Micro Scale Considering Physically Disabled Users: Case Study of Mimar Muzaffer Campus, Selcuk University

transport (national / regional scale) or by pedestrian, bicycle, car, public transport etc. (city / town scale) for a defined threshold of time or distance (e.g. 500 meters, 1 kilometres, 1000 kilometres or 5 minutes, 60 minutes, 24 hours etc.) (Kuntay 1976ab, Kuntay 1990, Halden et al. 2000).

The accessibility measures could generally help decision makers working in architecture, urban and regional planning and geography related disciplines to

- identify regions that have inadequate or excessive service,

- select appropriate sites for new or re-located services,

- test and improve the performance of the transportation system.

That is why, accessibility measures can be accepted as key variables for supporting supply / demand, location / allocation and service/catchment area related planning policies and strategies at national, regional, and local levels (Makri 2002, Juliao 1999, Kuntay 1990, Halden et al. 2000, Radke and Mu 2000).

Numerous accessibility measures, ranging from simple to sophisticated, can be found in the accessibility modelling literature and are used extensively as a decision support tool in the transportation, geography and urban and regional planning related process. Some of the basic ones of these accessibility modelling related researches can be summarized as follows;

a) Travel time/distance measures, service/catchment areas (travel time or distance to nearest supply/demand calculated from Euclidian/Network-based costs) (see Ghio et al. 2007, Joseph et al. 2006, Fortney et al. 2000, Sylvie 2007, Brabyn 2002, O'Sullivan et al. 2000, Juliao 1999, Ebener et al. 2005, Liang \& Zhang 2018, Saghapour et al. 2017),

b) Cumulative opportunity measures (consider the total amount of demand/supply inside the catchment areas) (see Chapelet and Lefebvre 2005, Boulos et al. 2001, Nadine et al. 2006, Black et al. 2004, Goulias 2007, Gallego et al. 2014, Langford Fry \& Higgs 2012),

c) Population to provider ratio measures (supply to demand ratios, calculated inside the catchment areas) (see Luo 2004, Scott et al. 2006, Bagheri et al. 2006, Bauer et al. 2017, Higgs et al. 2017),

d) Kernel density measures (use the Gaussian kernel approach to calculate the density value of each demand/supply) (see Yang et 
al. 2006, Gibin et al. 2007, Matthew et al. 2009, G. Cheng et al. 2016, J. Q. Cheng, et al. 2013, Delso et al. 2017, Nieves, 2015),

e) Gravity-based measures (a combined indicator of accessibility and availability by considering the attractiveness of supply/demand) (see Kwan 1998, Chen 2000, Guagliardo 2004, Delamater 2018, Vadrevu \& Kanjilal 2016, Xu \& Cui 2012),

f) Two-step floating catchment area measures (2FCA) (repeat the process of catchment area calculation for both supply and demand points and consider both of the overlay areas (see Mitchel et al. 2008, Luo and Wang 2003, Luo 2004, Yang et al. 2006, Scott et al. 2006, (Langford et al. 2012, Ye et al. 2018).

In the light of the accessibility modelling literature, it can be easily observed that; although there are a large number of researches and modelling approaches on accessibility modelling on macro scales (such as national, regional, city and town scales), the researches on how to model access and circulation in micro scales (such as street, human, neighbourhood scales, that can be perceived with all the details of the urban space) seem to be extremely limited.

This study, which emerged from this lack of literature, proposes a Geographic Information System (GIS) supported methodology (GIS could be defined as a system that could store, query, analyse and visualize location based datasets) to demonstrate how physical obstacles / barriers such as walls, steps, stairs, pits, unfitted street furniture, other (garbage, rubbles, trees etc. that prevent access) etc. and transitions (ramps with appropriate slope, elevators and/or removing walls / steps) could be defined in GIS environment and how access and circulation in urban space could be modelled in (outdoor) urban space especially for the physically disabled users (users using wheelchair, bicycle, baby's car, market car etc.) considering these physical obstacles and transitions in the micro scale.

When physical accessibility is modelled in macro scale studies, the transportation infrastructure is generally introduced to the GIS environment as "road centre-lines" and the accessibility is generally/frequently modelled by taking these "road centre-lines" into consideration. The types of physical obstacles introduced to model on these macro scales are generally "road closures" because of disaster, maintenance or accident etc.

On the other hand, modelling of the accessibility or circulation process in micro scales have to be significantly different from the macro scale approaches in terms of their complexity, as micro scales need to consider all the details of the perceived urban space. In order to able to model physical accessibility in micro scale, "integrated regular network structures" are created to represent the sidewalks, squares, large / narrow passing's etc., instead of "road centrelines". The types of physical obstacles 
introduced to the model are the walls, steps, stairs, pits, unfitted street furniture, other (garbage, rubbles, trees etc. that prevent access etc.), instead of "road closures". Moreover, transition types and locations such as "ramps with appropriate slope, elevators and/or "removed walls / steps" etc are also introduced into the model in GIS environment.

The proposed accessibility modelling methodology in micro scale is conducted at Selcuk University, Faculty of Architecture, Mimar Muzaffer Campus Area. A polyline-based approach has been developed in GIS environment to demonstrate how physical barriers and transitions could be modelled in micro scale.

The results of the study is thought to provide an effective accessibility based decision support environment especially in "micro scale" by visualizing and presenting how the physical obstacles on the spaces that we use in our everyday life prevent us from access and circulation in space and how the elimination or removal of these physical obstacles and providing transitions will create a difference in the access and circulation process in a comparable manner.

This study is thought to be a guiding research in the accessibility modelling area because of its scale and could make a significant contribution to increase the accessibility levels of all kinds of physically disabled users (users using wheelchair, bicycle, baby's car, market car etc.) in the outdoor urban areas by demonstrating their circulation possibilities and capabilities.

Using the larger data sets of the proposed model, especially on the web environment, is of great importance in terms of understanding the access and circulation capabilities of particular urban indoor and outdoor spaces considering particular users, obstacles and transitions.

\section{METHODOLOGY}

The process of modeling physical accessibility in micro scale was applied in Konya Selcuk University, Faculty of Architecture, Mimar Muzaffer Campus.

The study consists of 4 main parts, which are listed below and described in detail;

- Constitution of continuous network structure to be used in the modeling process of physical accessibility at micro scale,

- Establishing a spatial database of barriers and transitions that physically affect the continuity of the accessibility / circulation,

- Modeling of physical accessibility at micro scale in the context of different before and after case scenarios,

- Conclusion 


\section{Constitution of Continuous Network Structure to Be Used in The Modeling Process of Physical Accessibility at Micro Scale:}

In this context, the approximate boundaries of the study area (Mimar Muzaffer campus area) is digitized and stored in a spatial GIS database using $30 \mathrm{~cm}$ resolution of Google satellite image of the nearby environment (Figure 1).

Figure 1. $30 \mathrm{~cm}$ resolution Google satellite image of the nearby environment

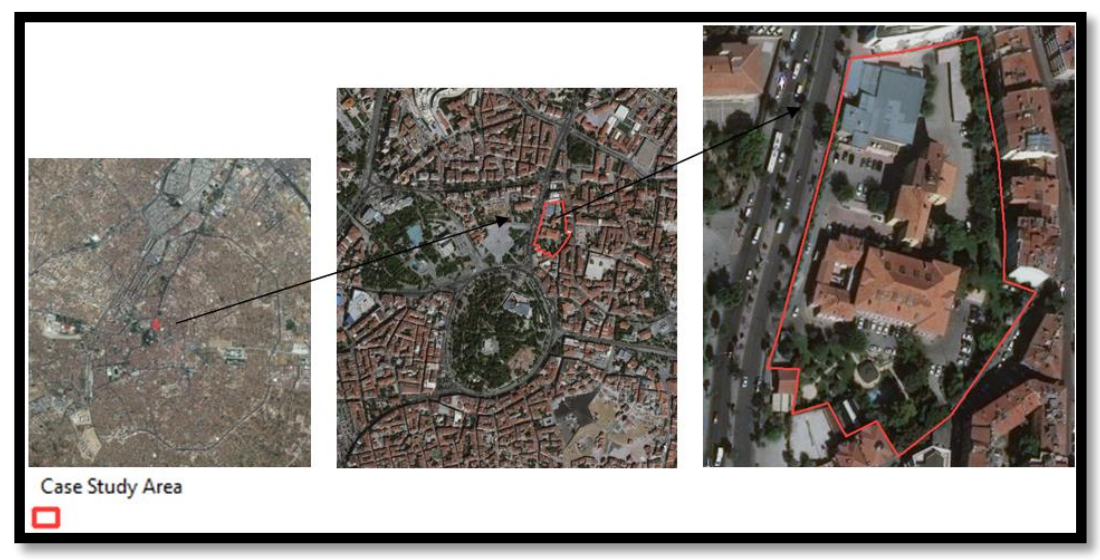

Although it is enough to model transportation networks at macro scales with only center-lines, in micro scales, a more complex modeling environment is required to define circulation in much more detail and in a continuous manner. By this reason, in order to able to model physical accessibility and / or circulation in micro scales, a regular continuous grid network structure is created within the working area boundaries by using the Fishnet function of GIS. With the help of the Fishnet function, the workspace could be covered with a network of rows and columns at the level of precision desired by the decision maker.

In this research, the study area is covered with a network of lines in 1 meter intervals. The level of sensitivity of the network structure can be regulated according to the sensitivity level required in the model and characteristics of the used computers (such as 0.5 meter, 1 meter, 2 meters, etc.).

Increasing the sensitivity level of the network structure increase the data size stored in the computer and increase the processing time in the modeling process. On the other hand, reducing the sensitivity level of the network structure could reduce reality in the model. However, it decreases the data size in the computer environment and reduces the processing time. Therefore, when deciding the level of sensitivity of the network structure, it is necessary to determine a reasonable level of network sensitivity considering the level of reality, area size, computer capacity and the aim of the study by the decision maker. 
In this research, a network structure with a 1-meter sensitivity level is created for the case study area, when the sensitivity level required in the model and characteristics of the computer used in this study is considered (Intel core i5 processor, $4 \mathrm{gb}$ ram, $1 \mathrm{gb}$ video card). However, as mentioned before, the sensitivity level can be increased or decreased according to the aim of the study and the characteristics of the computer systems used in the modeling process (Figure 2).

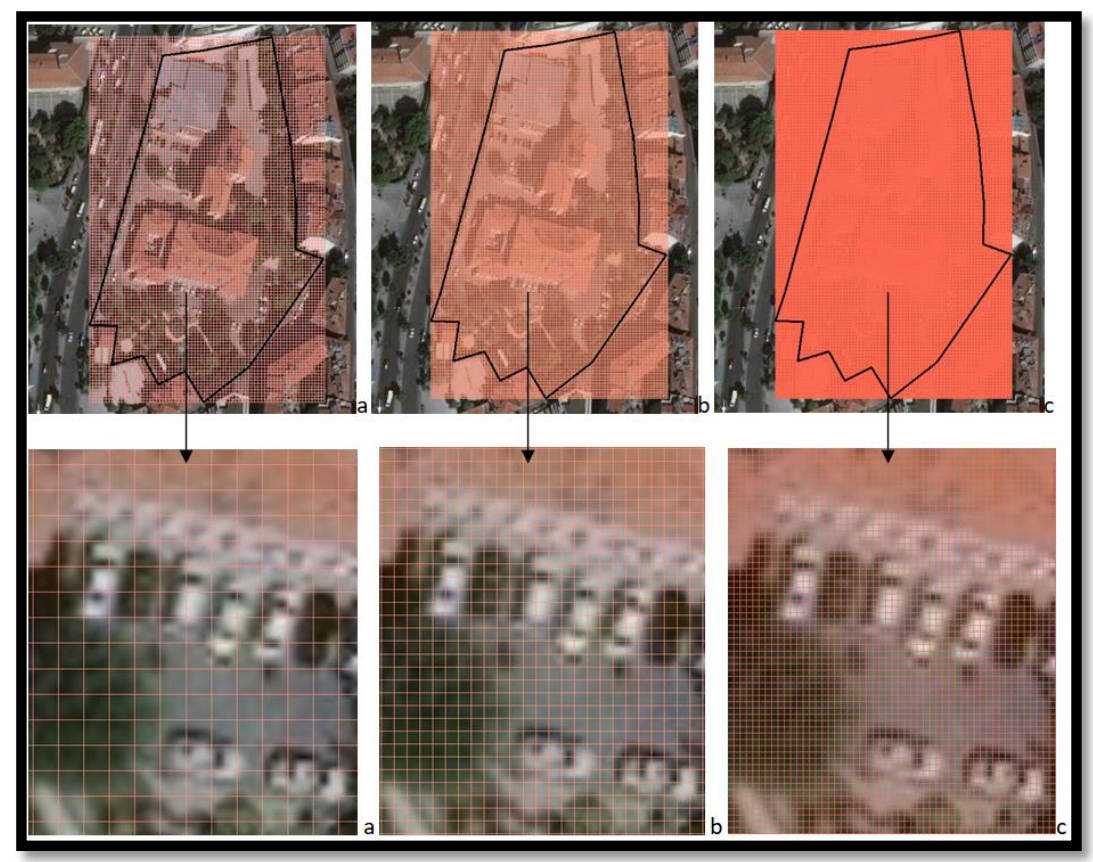

It is important to know that; the linear network structures generated by the "fishnet function" in GIS environment is not directly usable in the physical accessibility modeling process as the line components forming the network structure need to be separated from their intersection locations.

For this reason, firstly, the intersection locations of the linear network structure subject to the network analysis is exploded with the help of the "feature to line" function of GIS environment (Figure 3).
Figure 2. Examples of network structures at different sensitivity levels that can be used in micro level accessibility modeling processes (a: 2 meters, b: 1 meter, c: 0.5 meter sensitivity level) 


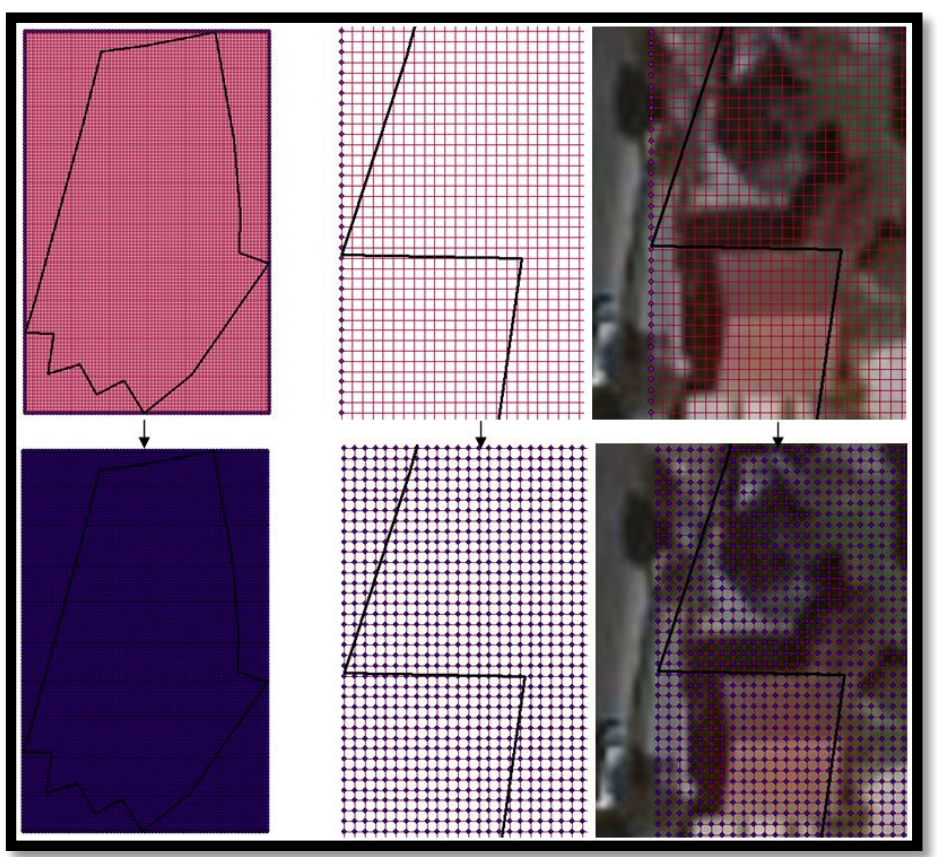

Figure 3. Exploding process of network structure with the help of the "feature to line" function of GIS environment (so that it can be separated from the intersection locations)

Figure 4. Elimination of network parts that are out of the study area and preparation for use in network analysis with "create network" function of GIS environment
In the next step, the network structure is simplified by deleting parts which are out of the study area by using "select by location" function of GIS environment. Finally, the network structure is introduced to GIS network analysis environment by using the "create network" function of GIS environment (see Figure 4).

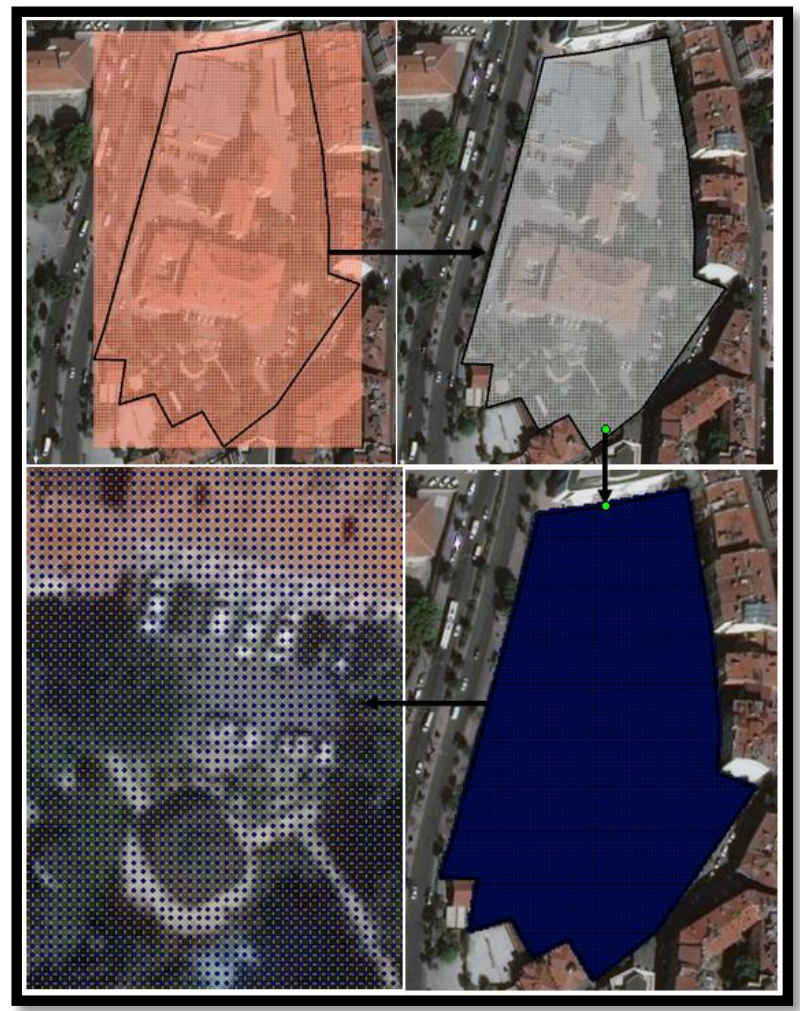


Geographic Information Systems (GIS) Based Accessibility Modeling Approach in Micro Scale Considering Physically Disabled Users: Case Study of Mimar Muzaffer Campus, Selcuk University

The presence of a continuous line in the network structure between intersections mean that; it is possible to access between locations without any physical obstacles.

\section{Establishing a Spatial Database of Obstacles / Barriers and Transitions That Physically Effect The Continuity of The Accessibility / Circulation}

In this part, the obstacles / barriers that physically divide / disrupt continuity of outdoor circulation such as buildings, landscape areas, walls, steps, stairs, pits, unfitted street furniture, other (garbage, rubbles, trees etc. that prevent access etc. and the transitions such as "ramps with appropriate slope, removing walls, steps and/or elevators" have been identified in Selcuk University, Mimar Muzaffer Campus study area especially considering physically disabled users (users using wheelchair, bicycle, baby's car, market car etc.) and a polyline based database has been developed in GIS environment to demonstrate how these physical barriers and transitions could be modeled in micro scale.

While a single object (a single point, line or area geometry that intersect a network segment in the form of a barrier) may be sufficient for the representation of barriers in macro scales (for example, when the path is closed due to accident, maintenance or disaster etc.), there is a necessity to use many objects together in GIS environment (point, line and/or area geometries) in an integrated and harmonious manner considering the sensitivity of network structure for the representation of the physical barriers and transitions in micro scales.

The details of the physical barriers and transitions created in GIS environment are given below;

The physical barriers/obstacles $\rightarrow$ The physical obstacles can be created in GIS environment by cutting the network structure by the barrier objects (point, line or area) in the regions where access is not possible. The presence of a point, line or area object that intersect with the network structure means that there are physical barriers on the network at that location; such as buildings, landscape areas, walls, steps, stairs, pits, unfitted street furniture, garbage, rubbles, trees etc. that does not allow mutual access.

In other words, the barrier objects are created on network structures and when a barrier object (point, line or area) is created in such a geometric form that intersect with the network structure, it means that it is not possible to access for physically disabled users (users using wheelchair, bicycle, baby's car, market car etc.) on that part of the network structure. 
Transitions $\rightarrow$ Transitions could be created on the barrier objects, where access is possible by partial or total removal of the barrier objects (point, line or area) on network structures. Providing a gap on a barrier object (either polyline or polygon) mean that the access is possible between locations through that gap (especially for users who are trying to access with wheelchairs, bicycles, children's cars, market cars, etc.). These gaps could be used to represent transitions in GIS environment and could be used in locations where access is provided by such as "ramps with appropriate slope", "removing walls or steps" or "elevators", etc.

In summary, the absence of an obstacle object (point, line or polygon barriers) on network structure means that the access is provided, spatial continuity is ensured and there is no any limitation on space that prevent circulation. On the other hand, the presence of an obstacle object on network structure means that access is not provided, spatial continuity is not ensured and there is limitation on space that prevent circulation such as walls, steps, stairs, pits, unfitted street furniture, other (garbage, rubbles, trees etc. that prevent access etc.) (figure 5).

Figure 5. Representation of accessibility between locations considering point, line and polygon types of barriers

(http://desktop.arcgis.com)

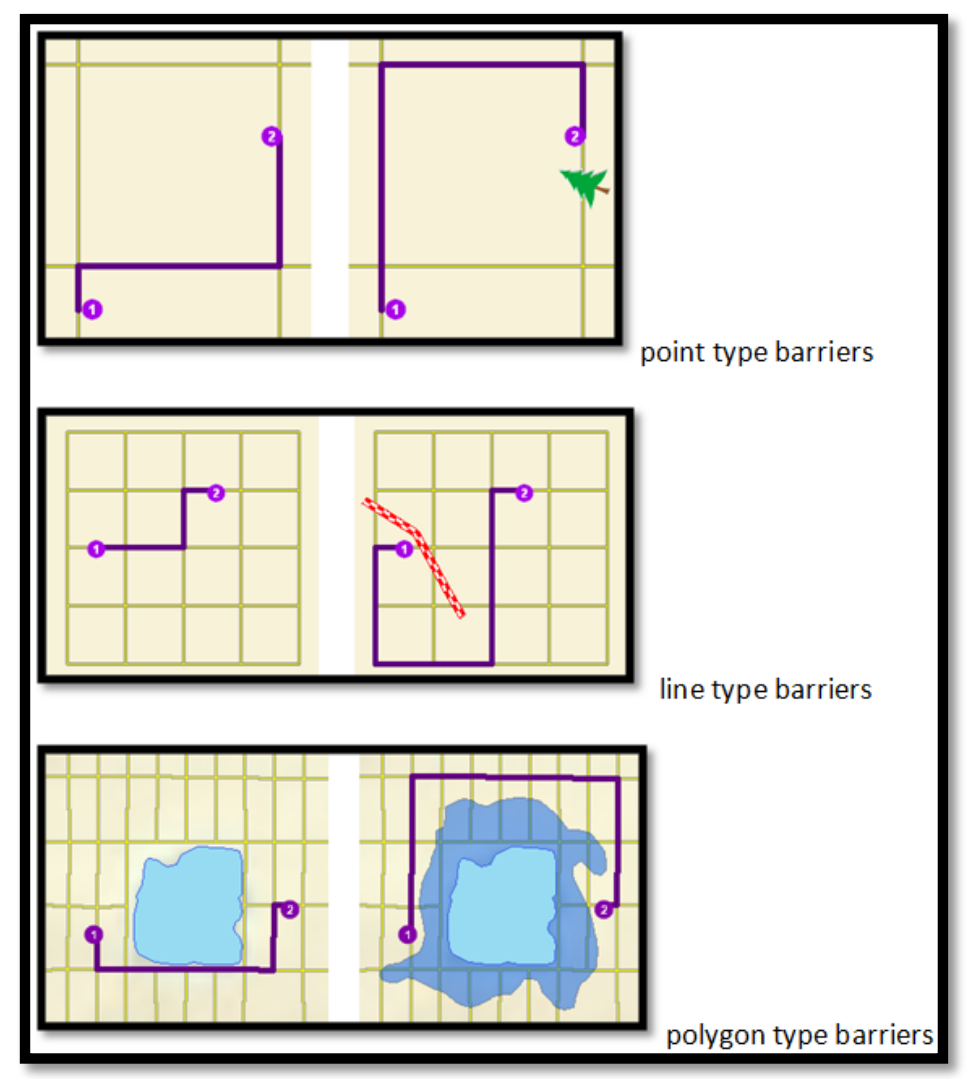

In this study, line type barriers are used to model physical obstacles and transitions in the study area, as lines could successfully enable representation of point and area type barriers 
Geographic Information Systems (GIS) Based Accessibility Modeling Approach in Micro Scale Considering Physically Disabled Users: Case Study of Mimar Muzaffer Campus, Selcuk University

because of their geometric characteristics (e.g.: a short line object could behave like a point type object or a polyline object which's starting coordinates are the same with the ending coordinates behave like a polygon type object). However, all of the three types of barriers (point, line and polygon) could also be used together to represent barriers in GIS environment.

Besides representation of different types of obstacles such as "walls, steps, stairs, pits, unfitted street furniture or other" and different types of transitions such as "ramps with appropriate slope", "removing walls, steps" or "elevators", barrier objects created in GIS environment could also represent different types of land use regions that have continuity of internal circulation such as pedestrian roads, landscape areas, vehicle roads or buildings etc. (see figure 6, figure 7).

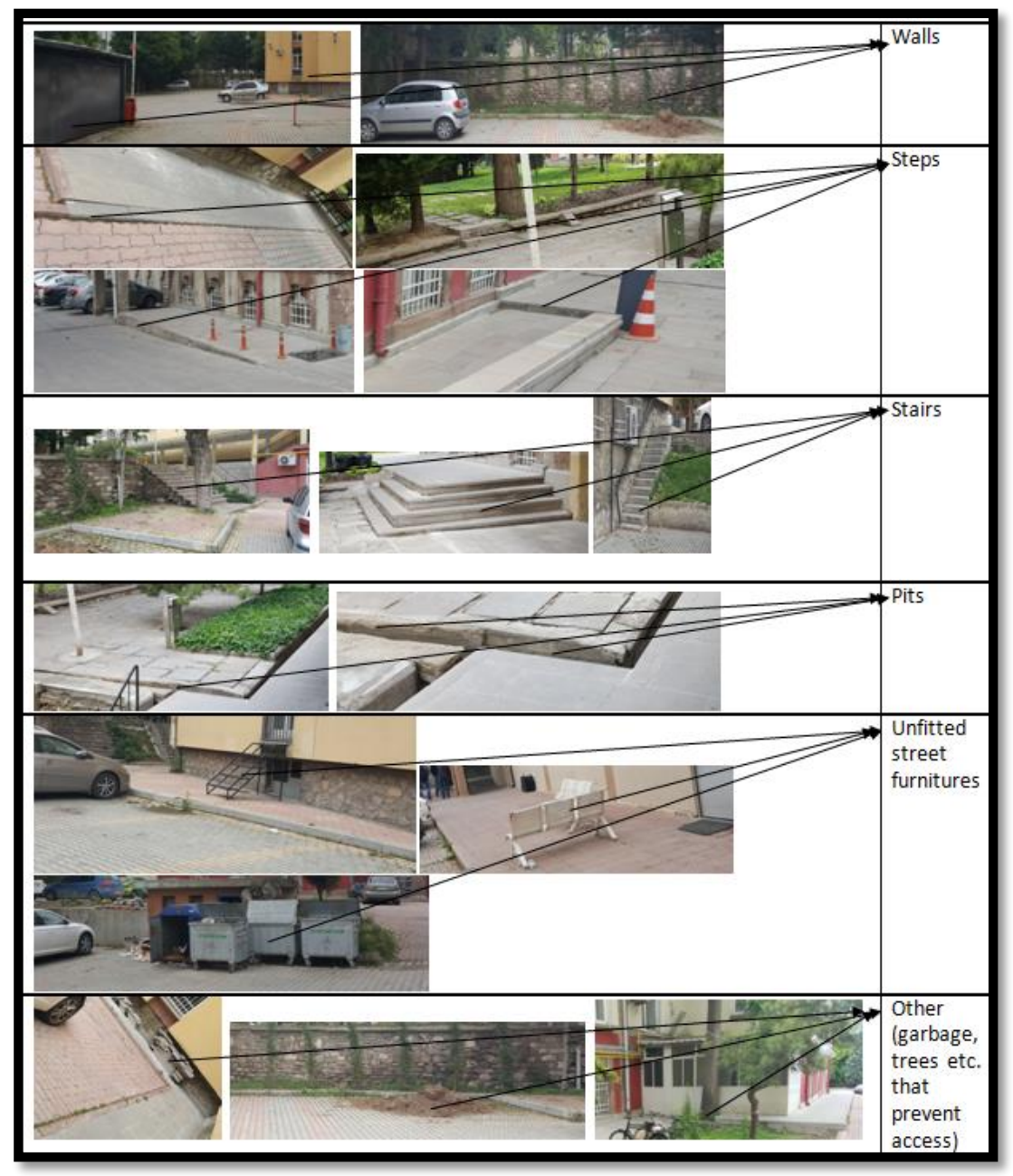

Figure 6. The type of physical obstacles that could be defined in a GIS database 


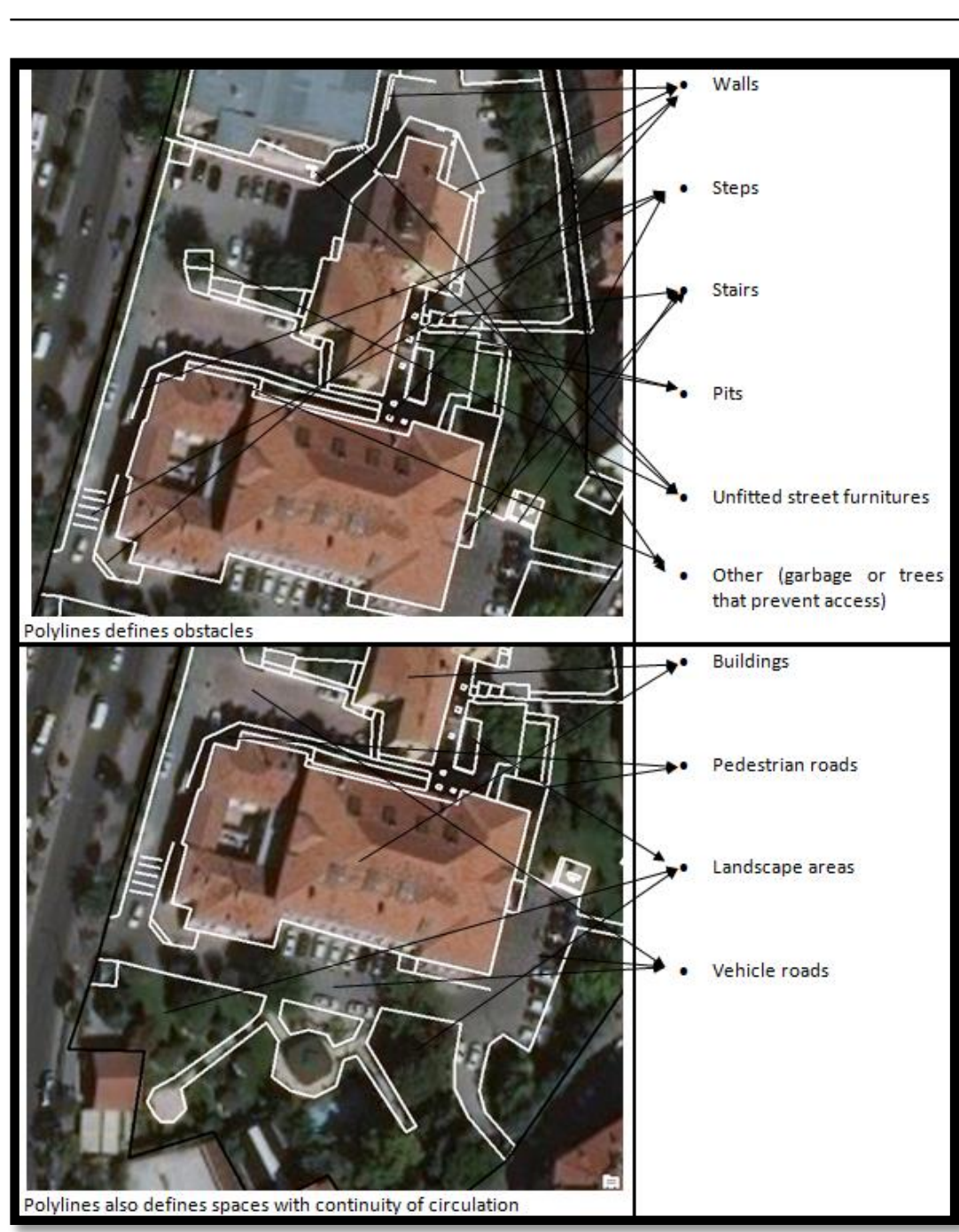

Figure 7. Examples of polyline objects that both represent "obstacles" and "different types of land use regions that have continuity of internal circulation"

For the study area, the physical obstacle objects created in polyline format are presented below (see figure 8, figure 9, figure 10, figure 11). As described above, in GIS environment, these polylines could also be used to identify different types of land use regions that have continuity of internal circulation. 
Geographic Information Systems (GIS) Based Accessibility Modeling Approach in Micro Scale Considering Physically Disabled Users: Case Study of Mimar Muzaffer Campus, Selcuk University
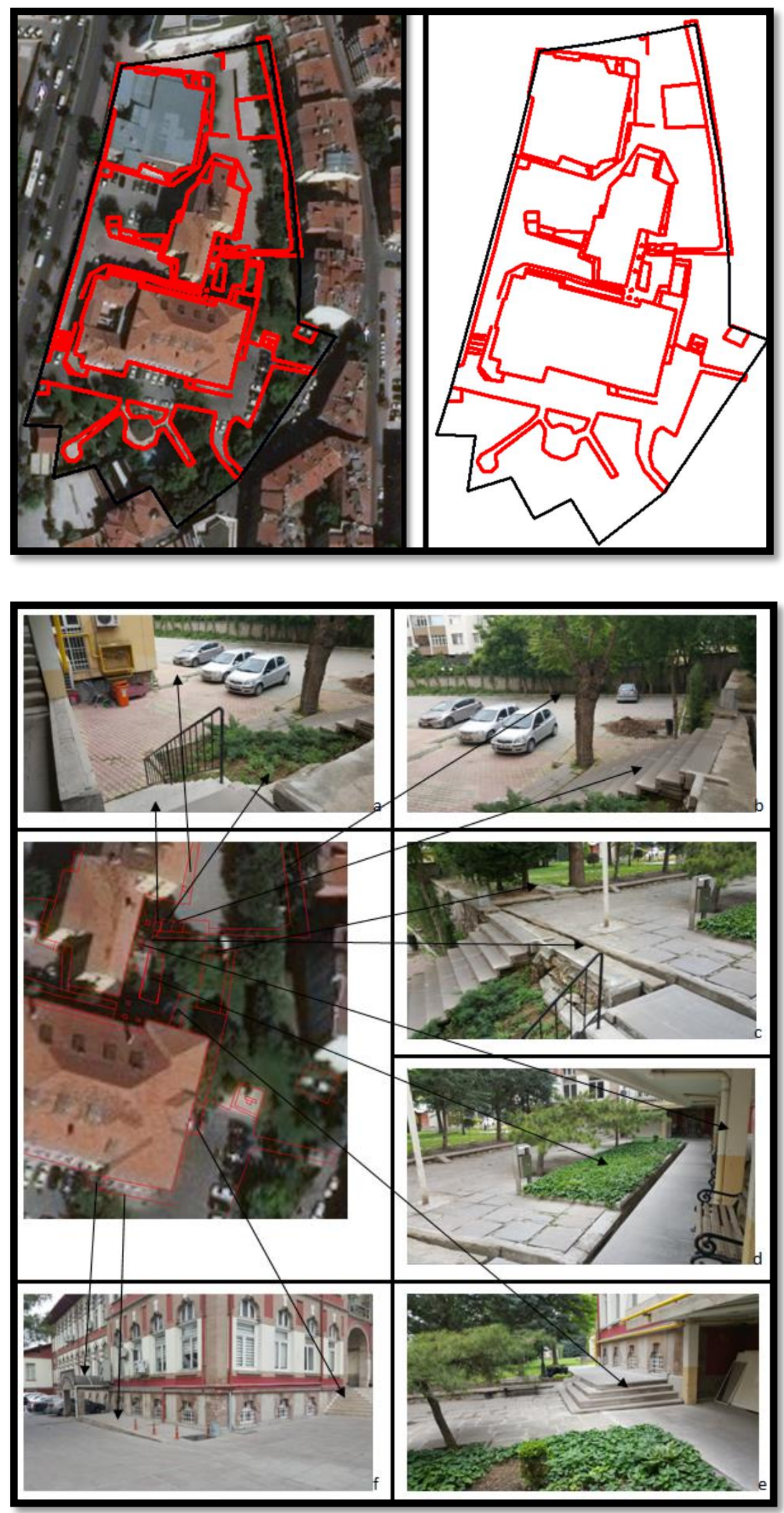

Figure 8. The created GIS based polyline objects which defines physical obstacles and different types of land use regions that have continuity of internal circulation in the study area

Figure 9. The examples of created polyline objects which define physical obstacles and different types of land use regions that have continuity of internal circulation (Some examples $\rightarrow$ a: stair, step, pedestrian road, b: stairs, step, landscape area, c: pits, step, landscape area, d: columns, step, landscape area, e: stairs, f: stairs in entrance, pedestrian road, step on pedestrian road,) 
Figure 10. The examples of created GIS based polyline objects which define physical obstacles and different types of land use regions that have continuity of internal circulation in study area (Some examples $\rightarrow$ a: stairs, wall, landscape area, b: building used for garbage storage, unfitted street furniture on pedestrian road used for ventilation, c: landscape area, pedestrian roads, $\mathrm{d}$ : step that separate pedestrian road, e: walls, long steps on vehicle road, f: partial steps, walls, landscape area

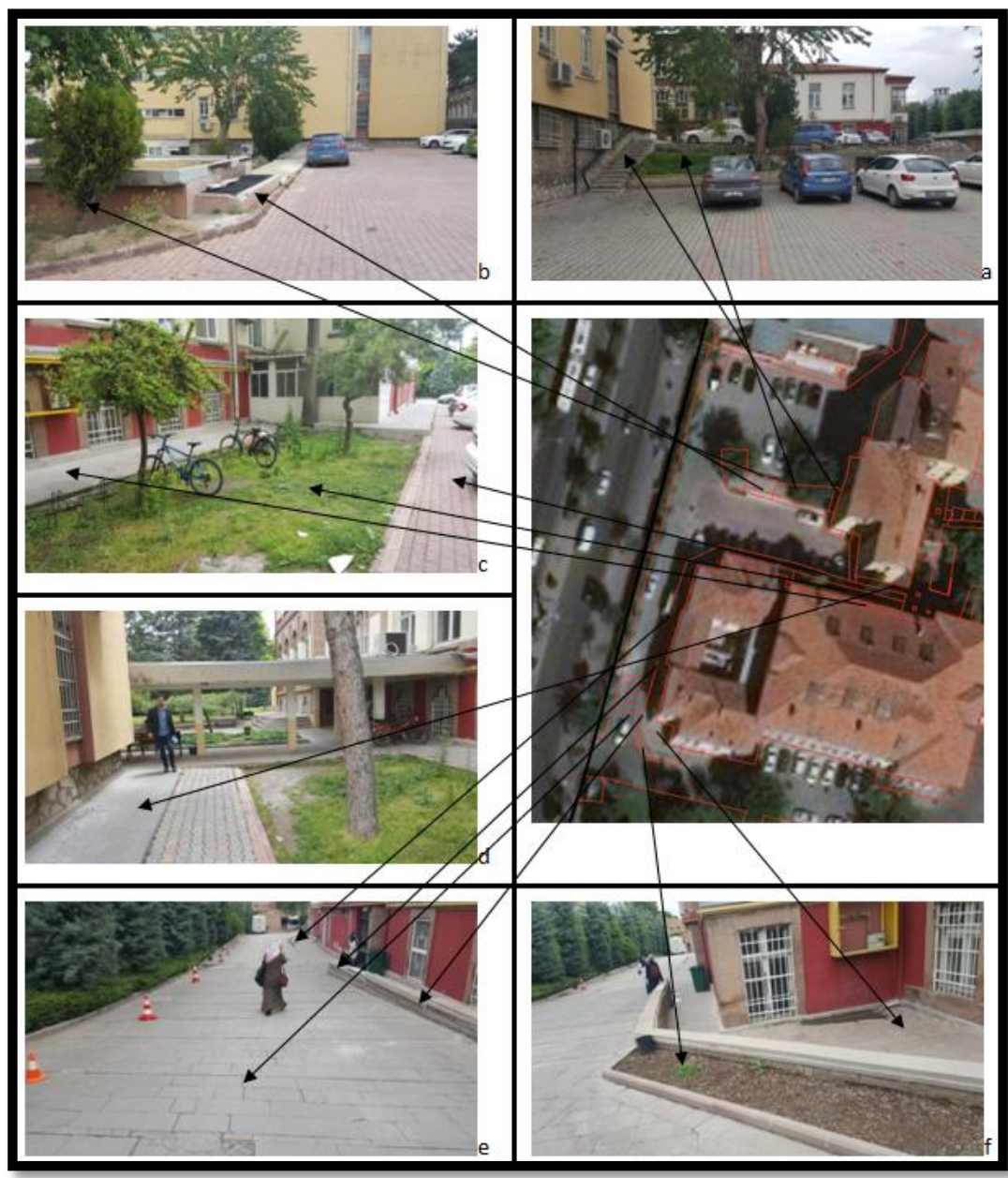

Modeling of physical accessibility at micro scale in the context of different before and after case scenarios

In this section of the research, by using the previously created model components of "network structure" and "physical obstacle layer", the answers of the following questions are analyzed in a comparable manner through different scenarios in the GIS environment;

- how the physical obstacles in micro scale block the access / circulation in the study area?

- how the presence or absence of these obstacles will make a difference in the access / circulation?

The base map that defines the main entrance and exit locations of the buildings in the study area are given below in order to help understanding of the before and after case scenarios (figure 12). 


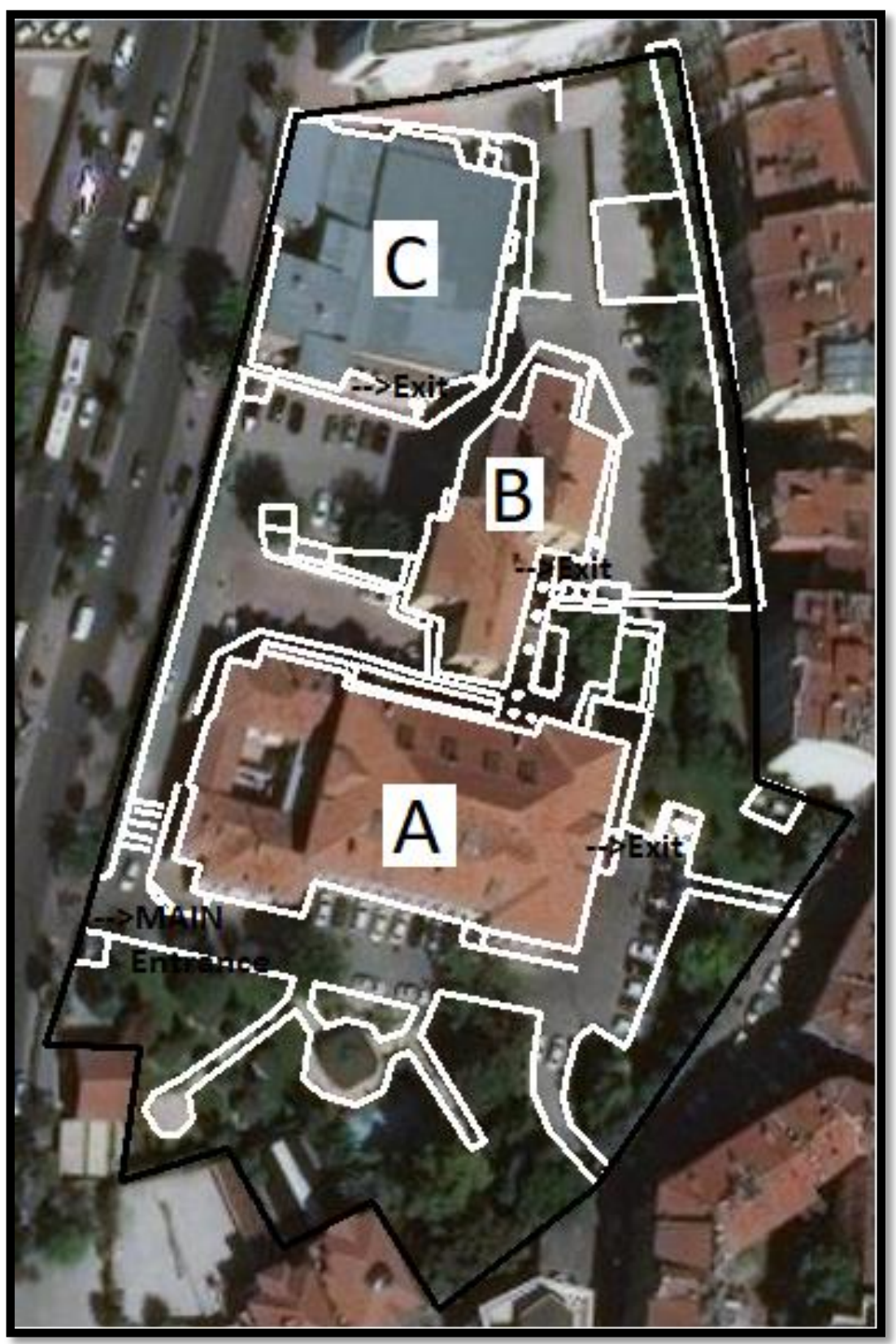

Figure 12. The base map that defines the main entrance / exit locations of the buildings in the study area

The first scenario (scenario 1) demonstrates the accessibility of locations starting from the exit of "building A" considering the effect of a stair obstacle. In other words, by the help of the scenario 1; decision makers could understand the effect of elimination of a step obstacle on circulation from the exit of "building A". Understanding from the figure 13 , elimination of a stair obstacle by the help of the transitions triggers a huge accessibility / circulation zone for the physically disabled users (such as people with wheelchairs, bicycles, baby's car or market's car etc.) (see figure 13). 
Figure 13. Scenario $1 \rightarrow$ The accessibility / circulation starting from the "building A" exit; a) the obstacle (stairs) b) accessibility / circulation before eliminating the stairs obstacle c) accessibility / circulation after eliminating the stairs obstacle (Blue point $\rightarrow$ is the starting location, Grid zone $\rightarrow$ is the accessible region starting from the "building A" exit)

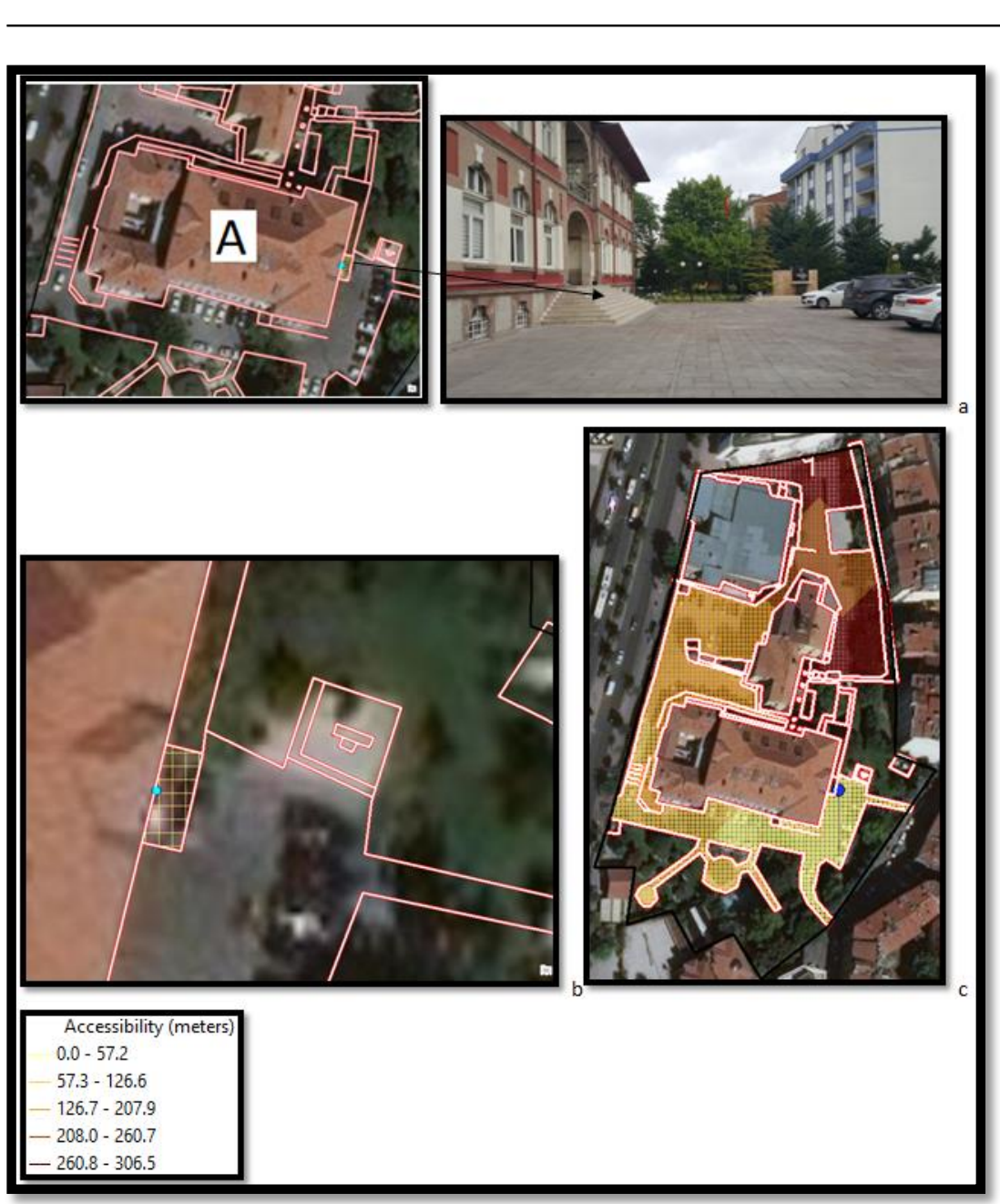

The second and third scenario (scenario 2 and scenario 3) demonstrate the accessibility of locations starting from the exit of "building B" considering the effect of step and stairs obstacle. In other words, by the help of the scenario 2 and 3; decision makers could understand the effect of elimination of a step and stair obstacle on circulation starting from the exit of "building B". Understanding from the figure 14 and figure 15, elimination of step and stair obstacle triggers a huge accessible zone for the physically disabled users (such as people with wheelchairs, bicycles, baby's car or market's car etc.) (see figure 14 and figure 15). 
Geographic Information Systems (GIS) Based Accessibility Modeling Approach in Micro Scale Considering Physically Disabled Users: Case Study of Mimar Muzaffer Campus, Selcuk University
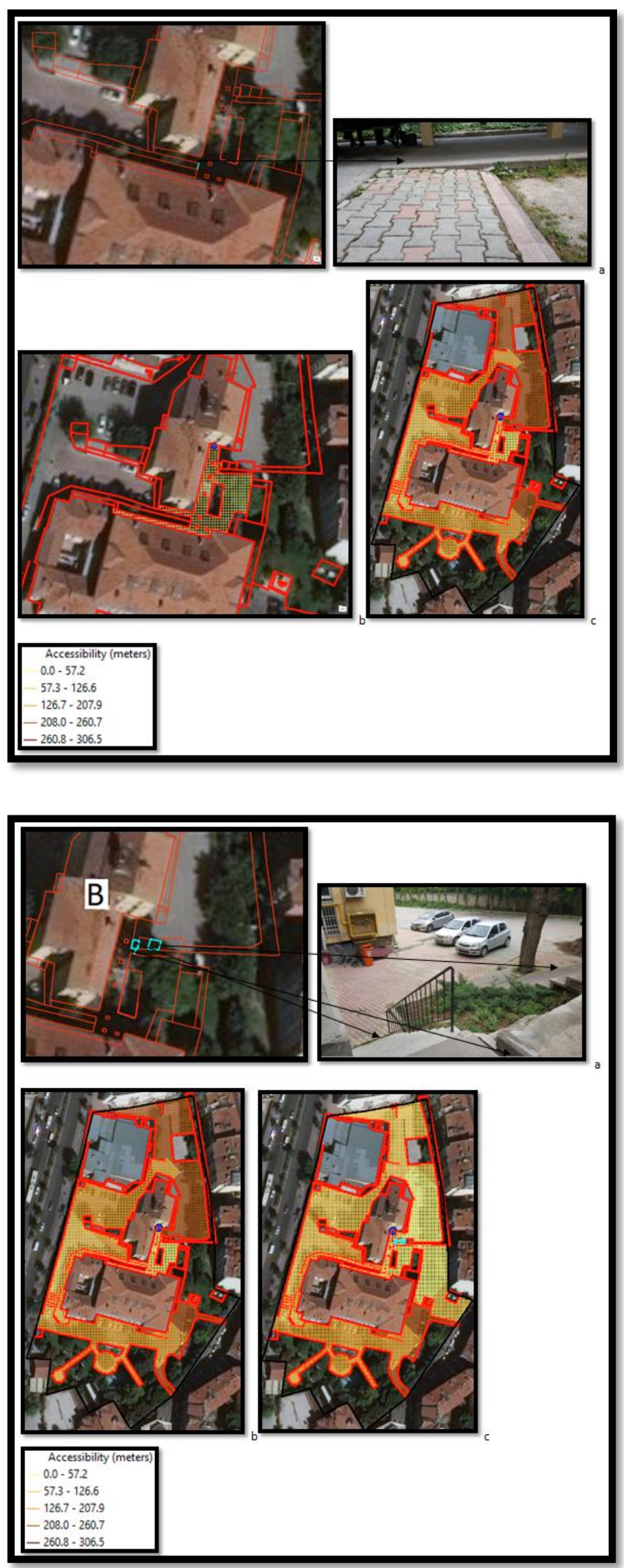

Figure 14. Scenario $2 \rightarrow$ The accessibility / circulation starting from the "building B" exit; a) the obstacle (step) b) accessibility / circulation before eliminating the step obstacle c) accessibility / circulation after eliminating the step obstacle (Blue point $\rightarrow$ is the starting location, Grid zone $\rightarrow$ is the accessible region starting from the "building B" exit)

Figure 15. Scenario $3 \rightarrow$ The accessibility / circulation starting from the "building B" exit; a) the obstacle (stairs and pits) b) accessibility / circulation before eliminating the steps and pits obstacle c) accessibility / circulation after eliminating the steps and pits obstacle (Blue point $\rightarrow$ is the starting location, Grid zone $\rightarrow$ is the accessible region starting from the “building B" exit) 
The fourth scenario (scenario 4) demonstrates the accessibility of locations starting from the exit of "building C" considering the effect of step and unfitted street furniture obstacles. In other words, by the help of the scenario 4; decision makers could understand the effect of elimination of a step and unfitted street furniture obstacle on circulation starting from the exit of "building C". Understanding from the figure 16, elimination of the step and unfitted street furniture obstacles triggers a huge accessible zone for the physically disabled users (such as people with wheelchairs, bicycles, baby's car or market's car etc.) (see figure 16).

Figure 16. Scenario $4 \rightarrow$ The accessibility / circulation starting from the "building C" exit; a) the obstacle (step and unfitted street furniture) b) accessibility / circulation before eliminating the steps and unfitted street furniture obstacle c) accessibility / circulation after eliminating the steps and unfitted street furniture obstacle (Blue point $\rightarrow$ is the starting location, Grid zone $\rightarrow$ is the accessible region starting from the "building C" exit)

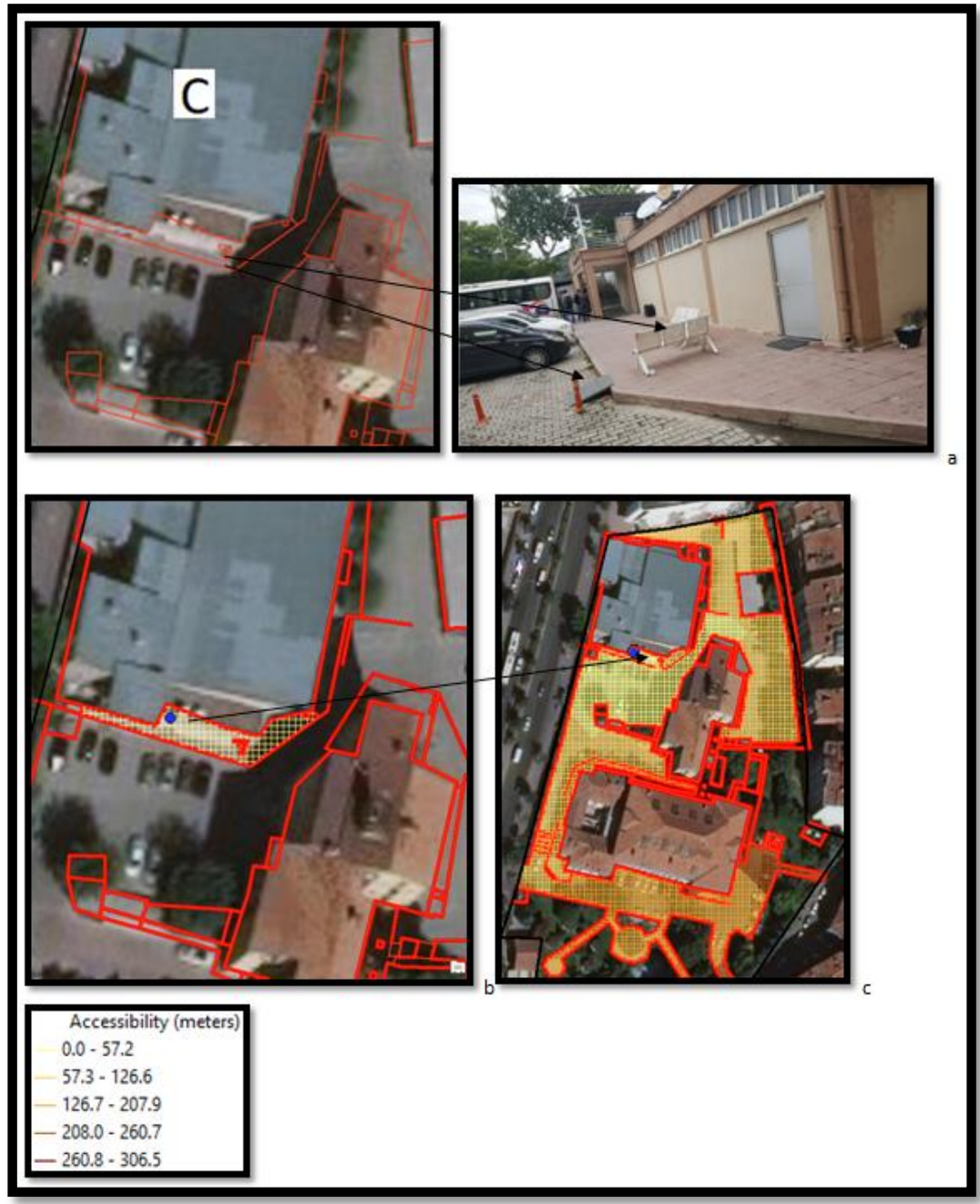

Starting from the exit of buildings, the grid zone represents the accessible zones where colors mean distance to starting point / location (exit of building A, B, C). Light colors mean that the location is close to starting location and darker colors mean that the location is far to the starting location. The locations that have no color mean that there is no access to this location by the users. 


\section{CONCLUSION}

This study demonstrates a GIS-supported methodology on how physical obstacles / barriers such as buildings, landscape areas, walls, steps, stairs, pits, unfitted street furniture, other (garbage, rubbles, trees etc. that prevent access) etc. can be defined in the GIS environment and how access and circulation could be modeled for the physically disabled users (users using wheelchair, bicycle, baby's car, market car etc.) against these physical obstacles in the micro scale.

The proposed methodology is conducted at Selcuk University, Faculty of Architecture, Mimar Muzaffer Campus Area. A polylinebased database has been developed to demonstrate how physical barriers should be modeled in micro scale in a GIS environment. The results of the case study provide an accessibility based decision support environment especially in micro scale by visualizing and presenting how physical obstacles on urban space that we frequently use in our daily life prevent us from access and circulation and how the elimination or removal of these physical obstacles will create a difference in access and circulation in a comparable manner.

As the researches of accessibility modeling in micro scales (such as street, human, neighborhood scales) considering the space in detail is extremely limited, this work is thought to be one of the pioneering works in its area.

This research is thought to make an important contribution to increase the accessibility levels of physically disabled users (users that use wheelchair, bicycle, baby's car, market car etc.) in the outdoor urban areas and could effectively help decision makers to demonstrate their circulation possibilities and capabilities.

As a future work, adaptation of the proposed model, to the web environment, could create a vital effect in terms of understanding the access and circulation capabilities of particular urban spaces considering different types of users, physical obstacles and transitions by the large segments of the society, decision makers, researchers and especially by the physically disabled users.

\section{REFERENCES}

Bagheri, N., Benwell, G. L., Holt, A., (2006). Primary health care accessibility for rural Otago: "a spatial analysis". Health Care \& Informatics. Review Online

Bauer, J., Muller, P., Maier, W., \& Groneberg, D. A. (2017). Orthopedic workforce planning in Germany - an analysis 
of orthopedic accessibility. Plos One, 12(2). doi:ARTN e017174710.1371/journal.pone.0171747

Black M., Ebener, S., Vidaurre, M., Aguilar, P. N., El Morjani, Z., (2004). Using GIS to Measure Physical Accessibility to Health Care, Health GIS Conference Proceedings, International ESRI User Conference. San Diego

Boulos, M. N., Roudsari, A. V., Carson, E. R., (2001). Health Geomatics: An Enabling Suite of Technologies in Health and Healthcare, Journal of Biomedical Informatics. Volume 34, Issue 3, June 2001, Pages 195-219. (Published: 22 September 2006)

Brabyn L., Skelly C., (2002). Modeling population access to New Zealand public hospitals International Journal of Health Geography. volume 1, page 1: 3. Published online 2002 November 12. DOI: 10.1186/1476-072X-1-3

Chapelet P., Lefebvre B., (2005). Contextualizing the Urban Healthcare System. Methodology for developing a geodatabase of Delhi's healthcare system, CSH Occasional Paper $N^{\circ} 11$. Publication of the French Research Institutes in India. Rajdhani Art Press. New Delhi (135 pages)

Chen, Q., (2000). Measuring Accessibility in GIS, http://mather.ar.utexas.edu/students/cadlab/ chen/measuring_accessibility_in_gis.htm

Cheng, G., Zeng, X. K., Duan, L., Lu, X. P., Sun, H. C., Jiang, T., \& Li, Y. L. (2016). Spatial difference analysis for accessibility to high level hospitals based on travel time in Shenzhen, China. Habitat International. 53, 485-494. doi:10.1016/j.habitatint.2015.12.023

Cheng, J. Q., Bertolini, L., le Clercq, F., \& Kapoen, L. (2013). Understanding urban networks: Comparing a node-, a density- and an accessibility-based view. Cities, 31, 165176. doi:10.1016/j.cities.2012.04.005

Delamater, P. L. (2018). Comment on "A Conceptual Framework for Quality Healthcare Accessibility: a Scalable Approach for Big Data Technologies". Information Systems Frontiers, 20(2). 303-309. doi:10.1007/s10796-0189829-8

Delso, J., Martin, B., Ortega, E., \& Otero, I. (2017). A Model for Assessing Pedestrian Corridors. Application to VitoriaGasteiz

City (Spain). Sustainability, 9(3)..doi:ARTN 43410.3390/s u9030434

Ebener, S., El Morjani, Z., Ray, N., Black, M., (2005). Physical Accessibility to health care: From Isotropy to Anisotropy, The Global Geospatial Magazine.GIS@development

Fortney, J., Rost, K., and Warren, J., (2000). Comparing Alternative Methods of Measuring Geographic Access to Health 
Geographic Information Systems (GIS) Based Accessibility Modeling Approach in Micro Scale Considering Physically Disabled Users: Case Study of Mimar Muzaffer Campus, Selcuk University

Services, Journal Health Services and Outcomes Research Methodology, springer, Volume 1, Number 2 / June, 2000. p: $173-184$

Gallego, J. A. G., Nieto, R. B., Labrador, E. E. R., Cabanillas, F. J. J., \& Jeong, J. S. (2014). An Accessibility Analysis to the City Bus Stops in Merida (Spain). Boletin De La Asociacion De Geografos Espanoles(64), 249-+.

Ghio, C., Mark L., Abdulkadir, N., Ahmed, A., (2007). Health GIS Tools and applications informing decisions in Yemen, Geospatial

Application Papers, http://www.gisdevelopment.net/app lication/ health/overview/ me05_012a.htm

Gibin, M., Longley, P., \& Atkinson, P., (2007). Kernel density estimation and percent volume contours in general practice catchment area analysis in urban areas, In Proceedings of the GIScience research UK conference (GISRUK), Ireland: Maynooth

Goulias, K. G., (2007). An Optimal Resource Allocation Tool for Urban Development Using GIS-based Accessibility Measures and Stochastic Frontier Analysis, University of California, Santa Barbara California PATH Research Report, UCB-ITS-PRR-2007-7

Guagliardo, M. F., (2004). Spatial accessibility of primary care: concepts, methods and Challenges, International Journal of Health Geographics 2004, 3:3

Halden, D., Mcguigan, D., Nisbet, A., Mckinnon, A., (2000). Guidance On Accessibility Measuring Techniques And Their Application, Scottish Executive Central Research Unit, ISBN: 1842680013

Higgs, G., Zahnow, R., Corcoran, J., Langford, M., \& Fry, R. (2017). Modelling spatial access to General Practitioner surgeries: Does public transport availability matter? Journal of Transport \& Health, 6, 143-154. doi:10.1016/j.jth.2017.05.361

Joseph, P. M., Ashton, M. S., Richard, E. G., Pariwate, V., Mark, J. F., (2006). Evaluating Michigan's community hospital access: spatial methods for decision support, International Journal of Health Geographics 2006, p: 5-42

Juliao, R. P., (1999). Measuring Accessibility Using Gis Geocomputation-99 Conference, Mary Washington College, Virginia, USA

Kuntay, O., (1976a). Planlama Kontrol Aracı Olarak Fiziksel Erişilebilirlik Ve Çekim Gücü, Şehircilik Enstitüsü Dergisi, İTÜ, İstanbul, p: 33-47

Kuntay, O., (1990). Erişilebilirlik Kesin Bir Öncelik, Planlama Dergisi (Journal of the Chamber of City Planners), 90/1-2, 7 (in Turkish) 
Kwan, M. P. (1998). Space-time and integral measures of individual accessibility: a comparative analysis using a point-based framework, Geographical Analysis, 30, p: 191216

Langford, M., Fry, R., \& Higgs, G. (2012). Measuring transit system accessibility using a modified two-step floating catchment technique. International Journal of Geographical Information Science, 26(2), 193-214. doi:10.1080/13658816.2011.574140

Langford, M., Higgs, G., \& Fry, R. (2012). Using floating catchment analysis (FCA) techniques to examine intra-urban variations in accessibility to public transport opportunities: the example of Cardiff, Wales. Journal of Transport Geography, 25, 1-14. doi:10.1016/j.jtrangeo.2012.06.014

Liang, H. L., \& Zhang, Q. P. (2018). Assessing the public transport service to urban parks on the basis of spatial accessibility for citizens in the compact megacity of Shanghai, China. Urban Studies, 55(9), 1983-1999. doi:10.1177/0042098017705846

Luo, W., (2004). Using a GIS-based floating catchment method to assess areas with shortage of physicians, Health and Place, $10, \mathrm{p}: 1-11$

Luo, W., Wang, F., (2003). Measures of spatial accessibility to health care in a GIS environment: synthesis and a case study in the Chicago region Environment and Planning B: Planning and Design, volume 30, p: 865- 884

Makrí, M. B., (2002). Accessibility indices and planning theory, Eighth International Conference on Urban Transport and the Environment for the 21st Century. Urban Transport VIII, p: 37-46

Matthew R., McGrail, J., Humphreys, S., (2009). Measuring spatial accessibility to primary care in rural areas: Improving the effectiveness of the two-step floating catchment area method. Applied Geography, 29, p: 533-541

Mitchel, L., Gary, H., Jonathan R., Sean W., (2008). Urban Population Distribution Models and Service Accessibility Estimation. Computers, Environment And Urban Systems, 32, p: $66-80$

Nadine, S., Robert S. F., Stefan C. W. G., Darrin, G., (2006). Defining rational hospital catchments for non-urban areas based on travel-time, International Journal of Health Geographics, p: $5-43$

Nieves, J. J. (2015). Combining Transportation Network Models with Kernel Density Methods to Measure the Relative Spatial Accessibility of Pediatric Primary Care Services in Jefferson County, Kentucky. International Journal of 
Applied Geospatial Research, 6(3), 39-57. doi:10.4018/ijagr.2015070103

O'Sullivan, D., Alastair, M., John, S., (2000). Using desktop GIS for the investigation of accessibility by public transport: An isochrone approach, International Journal of Geographical Information Science, Vol. 14, No1, p: 85-104

Radke, J., Mu, L., (2000). Spatial Decompositions, Modeling and Mapping Service Regions To Predict Access To Social Programs, Geographic Information Sciences, Vol. 6, No. 2

Saghapour, T., Moridpour, S., \& Thompson, R. G. (2017). Measuring cycling accessibility in metropolitan areas. International Journal of Sustainable Transportation, 11(5), 381-394. doi:10.1080/15568318.2016.1262927

Scott, J., Larson, A., Jefferies, F. and Veenendaal, B., (2006). Smallarea estimates of general practice workforce shortage in rural and remote Western Australia, Australian Journal of Rural Health, Volume 14, Issue 5, published Online: 10 oct 2006, p: 209-213

Sylvie, D., (2007). Gis-Based Accessibility Analysis For Network Optimal Location Model, Article 407, Cybergeo, Systems, Modelisation Geostatistiques

Vadrevu, L., \& Kanjilal, B. (2016). Measuring spatial equity and access to maternal health services using enhanced two step floating catchment area method (E2SFCA) - a case study of the Indian Sundarbans. International Journal for Equity in Health, 15. doi:ARTN 8710.1186/s12939-0160376-y

Xu, K. S., \& Cui, W. G. (2012). A GIS-Based Assessment of Spatial Accessibility to County Hospitals: A Case Study of Dancheng County, China. Information and Business Intelligence, Pt Ii, 268, 454-460.

\section{Resume}

He was born in Ankara in 1976. He has an undergraduate degree from Gazi University, Faculty of Architecture, Department of City and Regional Planning (1999), has masters and Ph.D. degree from Middle East Technical University, Graduate School of Natural And Applied Sciences, Geodetic and Geographic Information Technologies Department (2003 and 2012). During his Ph.D. study, he was studied as a guest researcher at the University of California, Berkeley, Institute of Urban and Regional Development (20092010). He worked at Gazi University, Faculty of Architecture, Department of Urban and Regional Planning for 2 years as Research Assistant (2000-2002), at Middle East Technical University, Institute of Science, Geodesy and Geographical Information Technologies for 10 years as Research Assistant (2002-1012). He is still working at Selcuk University (newly Konya Technical University), Faculty of Architecture, Department of City and Regional Planning for 6 years as Dr. and Assist. Prof. Dr. since 2012. 
His research interests include Geographical Information Science, Spatial, Network and 3D Analysis in Urban and Regional Planning Related Processes, Urban Transportion Planning and Accessibility Modeling. He is married and has one child. 